\title{
O MÉTODO INTUITIVO E A PERCEPÇÃO SENSORIAL COMO LEGADO DE PESTALOZZI PARA A GEOGRAFIA ESCOLAR
}

\author{
Beatriz Aparecida ZanatTa*
}

\begin{abstract}
RESUMO: O artigo é uma contribuição para o entendimento da história da prática pedagógica da geografia escolar. Busca subsidiar a formação de professores com elementos que permitam a compreensão das concepçóes pedagógicas que, a partir do século XIX, passaram a nortear a prática de ensino de geografia. O principal objetivo é apresentar uma reflexão a respeito das contribuiçôes de Pestalozzi acerca da metodologia de ensino de geografia, assim como, da repercussão dessas idéias no ensino da geografia brasileira. A conclusão aponta para o entendimento de que muitas das idéias e princípios pestalozzianos encontramse presentes nas atuais propostas de ensino, porém enriquecidas pelas reflexôes de renomados teóricos do pensamento pedagógico e geográfico contemporâneo.
\end{abstract}

Palavras-chave: Ensino de geografia. Metodologia de ensino. Método intuitivo.

THE INTUITIVE METHOD AND SENSORIAL PERCEPTION

AS A LEGACY OF PESTALOZZI TO SCHOOL GEOGRAPHY

ABSTRACT: This paper is a contribution to the history of the pedagogic practice of school geography. It seeks to provide teachers training with elements allowing to understand the pedagogic conceptions that, from the XIX ${ }^{\text {th }}$ century onward, have guided the practice of geography teaching. The main objective is to present a reflection on both the contributions of Pestalozzi to the methodology of geography teaching and the impacts of his ideas on geography teaching in Brazil. Its conclusion highlights that many of the ideas and principles of Pestalozzi are present in the current propos-

Doutora em educação pela Universidade Estadual Paulista (UNESP/Marília) e professora da Universidade Católica de Goiás (UCG).E-mail: beanza@uol.com.br 
als of teaching, though enriched by the reflections of renowned theoreticians of the contemporary pedagogic and geographical thought.

Key words: Geography teaching. Teaching methodology. Intuitive method.

$\mathcal{E}$ ste texto busca expor algumas idéias de Pestalozzi sobre metodologia de ensino de geografia. A intenção é propiciar uma melhor compreensão da proposta de ensino de geografia elaborada no momento de sua inserção no currículo escolar. A primeira parte do texto apresenta uma síntese do processo de inclusão da geografia como disciplina obrigatória no sistema escolar alemão, enfatizando a contribuição do pensamento de Pestalozzi para o ensino dessa ciência; a segunda trata da repercussão do método de Pestalozzi no ensino de geografia no Brasil.

\section{O pensamento de Pestalozzi}

O século XIX demarca um período decisivo para a história do pensamento geográfico pois, nele, a geografia alcança seu status científico, ao mesmo tempo em que é reconhecida como disciplina obrigatória nos programas de ensino primário e secundário. Esse reconhecimento decorre de uma série de acontecimentos sociais, econômicos, políticos desencadeados ao longo dos séculos XVII, XVIII e XIX.

Com efeito, o século XVII marcou o início da educação pública estatal prussiana, cujo objetivo era propiciar o engrandecimento do Estado. Luzuriaga (1959, p.151) esclarece que, do ponto de vista das autoridades prussianas, a educação respondia à "(...) necessidade de contar com súditos dóceis, bons soldados e funcionários idôneos".

No século XVIII, essa preocupação acentuou-se ainda mais. Em 1763, Frederico II promulgou um regulamento geral ${ }^{1}$ para as escolas elementares, o qual tornava obrigatório, dos 5 aos 13 ou 14 anos, o ensino para toda a população masculina. Foi nesse século que começaram a ser construídas por Pestalozzi as formulações mais incisivas sobre as transformaçóes pedagógicas.

Em meados do século XIX, uma nova lei (1839) proibia empregar crianças menores de 9 anos que não tivessem freqüentado a escola no mí- 
nimo por três anos (Capel, 1988). Em 1870, a obrigatoriedade de escolarização já era um fato generalizado por toda a Prússia. O processo que havia iniciado timidamente no final do século XVIII, um século mais tarde se convertia numa realidade em que todas as crianças, entre os 6 e os 15 anos, eram obrigadas a freqüentar a escola. A veracidade dessas informações pode ser comprovada estatisticamente por meio da redução do analfabetismo entre a população adulta prussiana. Em 1870, a porcentagem de analfabetos com mais de 10 anos era de $10 \%$ entre os homens e $15 \%$ entre as mulheres, com índices às vezes inferiores a $5 \%$ em certas regiōes (idem, ibid.).

Como resultado dessa política, o sistema escolar alemão se converteu em um modelo para os demais países europeus. Não foi apenas o desaparecimento do analfabetismo na Prússia, na primeira metade do século XIX, o foco da atenção dos europeus. A rede de escolas públicas da Prússia, que gradativamente se estendeu pelas demais unidades políticas alemãs, foi também muito admirada, conforme se depreende do relato elaborado em 1866 pelo inspetor de ensino da França, J. M. Baudoin:

(...) em nenhuma parte, a instrução está tão difundida, nem é dada com tanto interesse, nem dirigida com tanto cuidado. $\mathrm{O}$ mais pequeno povoado tem sua escola primária; a mais insignificante cidade, seu ginásio, suas escolas médias, perfeitamente organizadas, dotadas e cuidadas. Na Alemanha todos se interessam pela juventude: os mais altos personagens e as mais ilustres senhoras lhes dedicam seu tempo, seu dinheiro, sua experiência, os melhores escritores redigem livros para as crianças; os poetas compõem, para as liçôes de ginástica e de canto, poesias que os mais ilustres compositores não têm desdenhado colocar música. Todo o povo alemão está convencido de que se ocupar da instrução da juventude é cumprir um dever pessoal e trabalhar para o futuro do país. Cada um, se faz voluntariamente Volkserzieher, mestre do povo, e contribui por sua vez para o progresso da instrução geral. (Apud Capel, 1988, p. 89)

Esse sistema escolar, organizado por meio de uma hierarquia de instituiçóes docentes, se estendia do ensino maternal ao ensino médio. Uma de suas características básicas residia na aplicação de modelos pedagógicos inovadores de Pestalozzi, baseados na atividade observação da natureza.

Johann Heinrich Pestalozzi (1746-1827), educador suíço, nasceu em Zurich. Foi influenciado pelo pensamento de Rousseau e por alguns aspectos do movimento romântico, como por exemplo o amor pela natu- 
O método intuitivo e a percepção sensorial como legado de Pestalozzi...

reza e a concepção organicista. Desde os tempos de estudante participou de movimentos de reforma política e social. Em 1774, fundou um instituto para órfāos, organizado como uma família e destinado a educar intelectual e moralmente os rapazes afiliados. Chamou a atenção do mundo por sua ação como mestre, diretor e fundador de escolas, particularmente da famosa escola de Yverdon, um verdadeiro laboratório de experimentos pedagógicos. Suas obras principais são Leonardo e Gertrudes (1781) e Como Gertrudes instrui seus filhos (1801), sendo que, na primeira, delineou suas idéias acerca da reforma política, moral e social.

Com base nas idéias postuladas por esse pedagogo, as escolas da Prússia foram reorganizadas, os métodos pestalozzianos adotados e as escolas normais fundadas para formar novos professores. Tamanha foi a influência de Pestalozzi na reestruturação da educação prussiana que esta passou a ser denominada "sistema escolar prussiano-pestalozziano".

Em todo esse esforço de expansão da escolaridade, a geografia esteve sempre presente nos programas. Isso porque, como explica Capel (1988, p. 90-91), “(...) a aplicação dos métodos pestalozzianos permitia converter facilmente a geografia local ou regional [Heimatkunde] em um ensino ativo e em contato com a natureza”.

Pestalozzi elaborou sua proposta pedagógica retomando de Rousseau $(1712-1778)^{2}$ a concepção da educação como processo que deve seguir a natureza e os princípios como da liberdade, da bondade inata do ser e da personalidade individual de cada criança. Libâneo (1991, p. 61), ao analisar as idéias mais importantes de Rousseau, destaca:

1) A preparação da criança para a vida futura deve basear-se no estudo das coisas que correspondem às suas necessidades e interesses atuais. Antes de ensinar as ciências, elas precisam ser levadas a despertar o gosto pelo seu estudo. Os verdadeiros professores são a natureza, a experiência e o sentimento. O contato da criança com o mundo que a rodeia é que desperta o interesse e suas potencialidades naturais.

2) A educação é um processo natural, ela se fundamenta no desenvolvimento interno do aluno. As crianças são boas por natureza, elas têm uma tendência natural para se desenvolverem.

Ao colocar em prática as idéias de Rousseau, Pestalozzi (1946, p. 13) defendeu uma educação não-repressiva e dedicou ampla atenção ao ensino como meio de desenvolvimento das capacidades humanas, como 
cultivo do sentimento, da mente e do caráter. Para ele, “(...) a educação verdadeira e natural conduz à perfeição, à plenitude das capacidades humanas".

Ciente da função social da escola, Pestalozzi postulou a difusão do saber universal a todas as classes sociais como condição para se alcançar a dignidade humana. A esse respeito, Manacorda (1989, p. 266) transcreveu as seguintes palavras de Pestalozzi:

O aluno, seja qual for a classe social a que pertença e a profissão a que esteja destinado, participa de certos elementos da natureza humana que são comuns a todos e constituem o fundamento das forças humanas. Nós não temos direito algum de limitar a qualquer homem a possibilidade de desenvolver todas as suas faculdades (...); não temos o direito de negar à criança a possibilidade de desenvolver nem que seja uma só faculdade, nem mesmo aquela que, no momento, julgamos não essencial para a sua futura profissão ou para o lugar que ele terá na vida.

Era propósito de Pestalozzi (1946) descobrir as leis que propiciassem o desenvolvimento integral da criança. Concebia a criança como um organismo que se desenvolve de acordo com leis definidas e ordenadas e contém em si todas as capacidades da natureza humana. Essas capacidades se revelam como unidade da mente, coração e mão (ou arte), e devem ser devolvidas por meio da educação intelectual, profissional e moral, estreitamente ligadas entre si.

A educação intelectual resulta da organização das impressões sensoriais obtidas pela relação homem-natureza. Nesse processo, a seleção das impressões recebidas da natureza transforma as representações confusas em conceitos precisos e claros. O meio essencial da educação intelectual é a intuição. Para Pestalozzi, a intuição não se limitava à mera visão passiva dos objetos, à contemplação das coisas, mas incluía a atividade intelectual por meio da qual eram criados os objetos. Conforme Pestalozzi (1946, p. 15): "Esse conhecimento pode ser manifestado de maneira elementar pelo número, pela forma e pela palavra, que são produtos da inteligência criados por intuições maduras e que devem ser considerados como meios para a progressiva precisão de nossos conceitos".

A educação prática refere-se ao aprender trabalhando, fazendo. Nesse ponto, Pestalozzi preocupou-se em relacionar conhecimentos e atividades práticas. Da mesma forma que a atividade intelectual necessitava de 
O método intuitivo e a percepção sensorial como legado de Pestalozzi...

exercício especial da mente, era indispensável para o desenvolvimento de habilidades exteriores exercitar os sentidos e os membros.

A educação moral ou religiosa era considerada por Pestalozzi como a de maior significado na formação do ser humano. Para ele, toda a educação intelectual se converte em um espectro quando não é vivificada por ela. A educação moral não consiste na instrução ou na ilustração da moral, mas na formação de valores e modos de agir coerentes. Como disse Pestalozzi (1946, p. 16), “(...) a educação moral mais que ensinada, tem de ser vivida. A vida educa. (...) E o fim da educação moral não é outro que o aperfeiçoamento, o enobrecimento interior, a autonomia moral".

Com a preocupação de viabilizar de modo articulado o desenvolvimento intelectual e moral do homem, Pestalozzi estabeleceu alguns princípios para o seu método de ensino, como: partir do conhecido ao desconhecido; do concreto ao abstrato, ou do particular ao geral; da visão intuitiva à compreensão geral, por meio de uma associação natural com outros elementos e, finalmente, reunir no todo orgânico de cada consciência humana os pontos de vista alcançados.

Dentre esses princípios, o que mais se destacou foi o da percepção sensorial como fundamento de todo o conhecimento. Como dizia Pestalozzi (1946, p. 63), “(...) a intuição da natureza é o único fundamento próprio e verdadeiro da instrução humana, porque é o único alicerce do conhecimento humano". O fundamental não era ensinar determinados conhecimentos, mas desenvolver a capacidade de percepção e observação dos alunos.

Esse princípio não era novo, mas o maior mérito atribuído a Pestalozzi deve-se ao método prático que empregou, colocando essa idéia sob um novo prisma. Neste aspecto, diferentemente da supervalorização dada por Coménio ${ }^{3}$ e Basedow ${ }^{4}$ às figuras de objetos para a realização do ensino, esse pedagogo defendeu que, para as primeiras experiências de aprendizagem, os objetos eram imprescindíveis e deveriam preceder as gravuras. Estas deveriam vir posteriormente, desempenhando a função de auxílio à criança na transição para o desenho, a escrita e a leitura. Ou seja, partir dos objetos e das impressóes que estes geravam, chegar ao pensamento ou idéia. Os sentidos deveriam entrar em contato direto com os objetos, depois o conteúdo do objeto observado se expressaria em palavras, permitindo a atividade mental. Esse entendimento tem como pressuposto o fato de Pestalozzi conceber a experiência sensorial como um processo ativo. Para ele, toda a mente está comprometida na experiência sensorial. $\mathrm{O}$ fato de 
cada objeto percebido ser colocado num mundo ordenado de espaço e tempo indicava que a percepção era um processo mental ativo. A mente encontrava-se especialmente ativa quando a criança começava a discriminar, analisar e abstrair as qualidades dos objetos. Nesse sentido, Pestalozzi, citado por Manacorda (1989, p. 263), afirma com profunda consciência didática o princípio do interesse e da curiosidade infantil como base para intervenção do professor: "O mestre (...) deveria antes de tudo procurar suscitar e manter vivo o interesse pela aprendizagem. A falta de diligência nas crianças depende sempre da falta de interesse e esta, por sua vez, depende do método de ensino adotado pelo mestre".

Isso envolve também o princípio da intuitividade e gradualidade no ensino, que leva do concreto ao abstrato. A esse respeito, Pestalozzi (apud Manacorda 1989, p. 264) acrescenta:

O vivo estímulo da curiosidade provoca tentativas que, se têm êxito positivo ou são encorajadas por outros, levam ao hábito de pensar. Deve-se agir sobre a mente das crianças com elementos tirados da realidade e não com regras abstratas, e se deve ensinar mais com a ajuda de objetos do que de palavras.

A base do método intuitivo é a "lição das coisas", acompanhada de exercícios de linguagem para se chegar às idéias claras. O método da "lição das coisas" se caracteriza por oferecer dados sensíveis à observação, indo do particular ao geral, do concreto experienciado ao racional, chegando por esse caminho aos conceitos abstratos. Daí a ênfase dada por Pestalozzi ao contato direto com a natureza e à observação da paisagem mediante a valorização da excursão e do trabalho de campo como pressuposto básico do estudo. Essa proposta constituiu um estímulo bastante promissor para uma nova abordagem dos conteúdos das diferentes disciplinas, em particular de temas próprios da geografia. As excursōes, as observações de campo, o uso de mapas e outras representações gráficas em muito contribuíram para dar vida ao ensino da geografia escolar.

Com essa preocupação, Pestalozzi (1946) destacou como um dos princípios básicos a serem ambicionados pelos professores o desenvolvimento das capacidades em sintonia com a aquisição do conhecimento. Esse fato pressupunha a aprendizagem como um processo espontâneo resultante de uma atividade livre, um produto vivo e original. Para tanto, o professor deveria buscar seu material no próprio meio que envolve o aluno, ou seja, em uma situação real. Dessa forma, a contemplação e a representação 
O método intuitivo e a percepção sensorial como legado de Pestalozzi...

da paisagem seriam os procedimentos fundamentais para o ensino da geografia local ou regional.

Deve-se a Pestalozzi a primeira tentativa de estabelecer o ensino da geografia com base na intuição. Até então o estudo dessa matéria limitavase a definições memorizadas, exercícios nos globos e cartas, a um mero jogo de palavras e símbolos. Ele inaugurou o ensino da geografia local, estabelecendo como ponto de partida o pequeno mundo da criança para o estudo dos fenômenos geográficos por círculos concêntricos em que primeiro se apresentava ao aluno o "próximo" ou concreto, para em seguida tratar de áreas distantes. Essas idéias também foram postuladas por Rousseau. A esse respeito, Proença, ([19-]; p. 45) destaca a seguinte argumentação de Rousseau: "É na natureza que a criança deve aprender geografia. A casa paterna, as terras circunvizinhas, os cursos de água da região, a marcha do sol no céu, a orientação, eis os primeiros centros de interesse para a criança. Depois viria o traçado da carta do terreno que estudou”.

Para Rousseau (1995, p. 210), a lição de geografia em vez de começar por intermédio dos globos e dos mapas, espécie de máquinas artificiais de representação, deveria começar pelo objeto mais próximo. Em sua obra, Emílio, encontra-se preconizado o ensino da geografia regional. Ao discutir sobre a metodologia de ensino das ciências, em particular da geografia, ele propôs tomar como ponto de partida as partes, sem, contudo, perder de vista o todo. Em suas palavras:

Eu gostaria, (...) de tomar a geografia por esses dois pontos e juntar ao estudo das revoluçôes do globo a medida de suas partes, começando pelo lugar em que habitamos. Enquanto a criança estuda a esfera e assim se transporta até os céus, trazei-a de volta à divisão da terra e mostrai-lhe primeiro sua própria morada.

Explicitando melhor sua idéia, Rousseau (1995, p. 210-211) pondera:

Seus dois primeiros pontos de geografia serão a cidade onde mora e a casa de campo de seu pai; depois, os lugares intermediários, os rios dos arredores e finalmente o aspecto do sol e a maneira de se orientar. Esse é o ponto de encontro. Que ela faça por si mesma o mapa de tudo isso, mapa muito simples e formado inicialmente por dois únicos objetos, aos quais ela acrescenta pouco a pouco os outros, à medida que vai conhecendo ou avaliando suas distâncias e suas posiçōes. (...) Que compreenda bem o que representam e tenha uma idéia nítida sobre a arte de traçá-los. 
Embora Pestalozzi seja considerado seguidor de Rousseau, parece importante atentar para uma diferença fundamental entre suas propostas de ensino. Rousseau valorizou os interesses imediatos do aluno em relação ao mundo que o cerca. Para ele o verdadeiro ensino deveria proceder diretamente da vida, da experiência, do sentimento. Já Pestalozzi atribuiu importância ao ensino como condição para a ativação das capacidades humanas. O que Pestalozzi (1946, p. 15) tinha em vista era que o conhecimento fosse desenvolvido por meio de atividades comuns da vida. "(...) Aprendese a fazer, e a conhecer, fazendo". Ele desejava elaborar um sistema de lições com vistas ao desenvolvimento do poder prático das crianças. Para tanto os objetos da natureza e da ciência eram supervalorizados. Defendendo a idéia de que é na natureza que a criança deve aprender geografia, Pestalozzi dispensou ousadamente o auxílio de esquemas, de mapas e livros-textos, tornando a geografia um assunto interessante para a educação elementar. O relato de um dos discípulos de Pestalozzi evidencia com clareza seu método de ensino:

Era no terreno que nós aprendíamos as primeiras noçōes de geografia. Um estreito vale nos arredores de Yverdon, no fundo do qual corre o Buron, era o ponto para onde de começo nos dirigíamos. Tínhamos, então, de contemplá-lo no seu conjunto e nas suas particularidades até que tivéssemos a intuição justa e completa do todo. Agora cada um de nós ia tirar punhados de um barro que ali existia, e com elle enchíamos as cestas que havíamos levado para esse fim. De volta ao castello, tomávamos os lugares que se nos haviam indicado diante de longas mesas, para modelar em argila o valle que havíamos observado. Nos dias seguintes, novas excursões e novas explorações, cada vez mais extensas que tinham como conseqüência a ampliação do nosso trabalho. Assim íamos indo até que ficasse terminado o estudo da bacia do Yverdon e nós pudéssemos, do alto do Montéla, abarcar-lhe o conjunto. Dávamos, então, por acabado o nosso mappa em relevo, e era tempo de passarmos à carta geographica, para cuja compreensão nos havíamos preparado [sic]. (Proença [19-], p. 49).

Porém, o estudo da geografia local não se limitava a questões de topografia. Aos fatos da geografia física e à intuição da terminologia peculiar se alternavam noções de geografia política, ou seja, tudo que na terra é obra do homem como, por exemplo, comércio, indústria, governo, leis, país, estado, município. Inicialmente o objeto de atenção era a família, a aldeia, a igreja, a casa da escola, o cemitério, o caminho da cidade. Depois, descreviam-se os homens nas suas ocupações, o padre, o juiz de paz, em resumo, a vida social. 
O método intuitivo e a percepção sensorial como legado de Pestalozzi...

Ao considerar a natureza o centro do currículo, Pestalozzi reformulou o currículo da escola elementar, tendo como referência disciplinas que considerava essenciais para o desenvolvimento intelectual: aritmética, desenho, geografia, canto e linguagem. Dessa forma, menosprezou as narrativas, a história e a literatura por julgá-las distantes da experiência viva. $\mathrm{Na}$ opinião de Eby (1962), essa posição revela pontos fracos da proposta educativa pestalozziana, como: não levar em conta o interesse das crianças por essas formas de atividade, não reconhecer o valor da função da imaginação no desenvolvimento do pensamento conceitual.

O método de Pestalozzi difundiu-se com maior ou menor expressividade por toda a Europa. Particularmente na geografia alemã importa destacar a grande influência de Pestalozzi nas propostas de ensino do geógrafo Carl Ritter, que sob inspiração pestalozziana, procurava evitar o acúmulo de informações desnecessárias que ninguém poderia assimilar (Capel, 1988)..$^{5}$

Nos Estados Unidos, as práticas do método intuitivo foram introduzidas em 1806, mas somente após 1860 receberam larga aceitação e utilização, como comprova a obra Primary object lessons for a graduated course of development de Calkins, originalmente publicada em 1861.

No Brasil, as idéias de Pestalozzi foram introduzidas pela tradução do manual de Calkins acima referido. A tradução e adaptação às condiçōes brasileiras foram feitas por Rui Barbosa, em 1880. Este manual, intitulado Primeiras liçôes de coisas foi aprovado pelo governo imperial como livro texto na formação de professores e publicado em 1886.

A repercussão das idéias de Pestalozzi nas propostas de ensino de geografia no Brasil

A história do ensino da geografia brasileira guarda algumas semelhanças com a européia - considerando-se, obviamente, a condição de país colonizado. A exemplo da Alemanha, o ensino de geografia já se fazia presente nas propostas curriculares e nos programas de ensino das escolas primárias muito antes de essa área do conhecimento ter sido institucionalizada pela produção acadêmica brasileira. ${ }^{6}$ Esse fato evidencia a ausência de sincronia entre o início do ensino de geografia brasileira e o processo de sua institucionalização. Igualmente, há que se considerar a presença no Brasil dos modelos pedagógicos predominantes no ensino europeu, no de- 
correr das primeiras décadas do século XIX, caracterizados pela pedagogia do ler, escrever e contar apoiada no verbalismo e no autoritarismo. Na Europa, no entanto, há algum tempo era expressivo o movimento de idéias que, em oposição ao ensino verbalista, difundia uma orientação pedagógica fundamentada na prática do ensino intuitivo.

Foi somente nas últimas décadas do século XIX, com a difusão dos argumentos em favor da educação pública popular, que surgiram, por meio dos intelectuais e políticos progressistas mais eminentes e das mais diversas tendências, expressivas manifestações contra o formalismo e o verbalismo do ensino em geral, em particular do ensino de geografia. $\mathrm{Na}$ opinião desses intelectuais, a educação da elite já não bastava. $\mathrm{O}$ acesso do povo à escola tornava-se imprescindível, à medida que o mundo do trabalho começava a se diversificar e a exigir alguns pré-requisitos como a leitura, a escrita, o conhecimento da aritmética, mesmo para o exercício das atividades mais simples na fábrica ou na prestação de serviços.

Dentre esses intelectuais destaca-se Rui Barbosa (1849-1923), ${ }^{7}$ como um dos mais representativos da classe média urbana brasileira, por seus argumentos lógicos e sistemáticos sobre a "Reforma Geral do Ensino" (primário e secundário da Corte e o superior em todo o País) decretada, em 1879, pelo ministro Leôncio de Carvalho.

Seus pareceres e discursos a respeito da problemática da educação criticam os vícios antigos do sistema educativo e evidenciam a sua preocupação em reverter o "quadro triste e sombrio do ensino" no Brasil.

Com essa preocupação, inspirou-se não somente nas idéias, mas nas próprias realizaçôes européias em matéria de educação. Seu projeto de reforma educacional traduzia a influência dos fundamentos científicos e psicológicos de uma didática mais adequada a um ensino objetivo, eficiente e criador, baseado na realidade e na natureza viva do aluno. Esse posicionamento coloca-o não apenas como herdeiro da tradição dos grandes didatas europeus do porte de Coménio, Pestalozzi, Froebel e Herbart, ${ }^{8}$ mas como precursor de um processo didático baseado em um método experimental de investigação.

De Herbart, Rui Barbosa utiliza os objetivos da educação fundados na moralidade, mediante o desenvolvimento da razão e a aprendizagem pela experiência. De Pestalozzi, o método intuitivo, de caráter objetivo e ativo que tem como núcleo orientador a "Lição de coisas", refinado pelo cientificismo positivista que dá forma ao método de investigação baseado 
O método intuitivo e a percepção sensorial como legado de Pestalozzi...

na experiência, na observação e na experimentação. Para ele, esse método deveria presidir o ensino de todas as matérias e não ser figurado isoladamente no currículo. A respeito desse método, Lourenço Filho (1956, p. 54) transcreve a seguinte afirmação de Rui Barbosa: “(...) É pela intuição real, não por descrições verbais que o ensino deve começar".

Seu método geral de ensino e sua teoria do conhecimento derivam dos fundamentos racionalista e empirista. A atitude empirista manifestase na aceitação do intuicionismo empírico de Pestalozzi. A atitude racionalista no reconhecimento dos esquemas do positivismo, especialmente os da escola dissidente de Littré e da concepção evolucionista de Spencer. Alguns anos depois de ter declarado que o conhecimento positivo é o único saber verdadeiro capaz de remodelar o mundo, ele reformulou seu pensamento: "(...) O positivismo é denominação pretensiosa e infiel, que quer elevar um método à altura de uma filosofia” (apud Lourenço Filho, 1956, p. 24). A postura intelectual de Rui Barbosa caracterizou-se por uma pluralidade de concepções teóricas. De acordo com Lourenço Filho (1956, p. 21), ele mesmo declarou: “(...) Percorri as filosofias, mas nenhuma me saciou: não encontrei repouso em nenhuma”. Sua filosofia não foi rigorosamente especulativa, nem empírica e, sim, uma filosofia da vida, inseparável da experiência pessoal. Partiu das dificuldades sociais como as sentia e vivia para definir a teoria da educação ou a reforma do homem e das instituições políticas.

$\mathrm{Na}$ qualidade de relator da comissão de instrução pública da Câmara, proclamou o sistema público de educação como fator de progresso econômico e político do país e defendeu a ação - urgente, imperiosa - do Estado em todos os níveis de ensino. No seu entendimento, a prosperidade de uma Nação encontrava-se diretamente vinculada à cultura do espírito popular por meio de uma sólida organização do ensino. Com essa convicção, ao elaborar a Reforma Geral do Ensino, introduziu o ensino intuitivo como uma das bases para a renovação pedagógico-didática da prática efetiva do ensino primário.

Rui Barbosa, (apud Lourenço Filho, 1956, p.121) caracteriza assim a prática do ensino intuitivo:

Educar a vista, o ouvido, o olfato; habituar os sentidos a se exercerem naturalmente sem esforço e com eficácia; ensiná-los a apreenderem os fenômenos que se passam ao redor de nós, a fixarem na mente a imagem exata das coisas, a noção precisa dos fatos, eis a primeira missão da esco- 
la, e, entretanto, a mais completamente desprezada na economia dos processos rudimentares que vigoram em nosso país. (...) a verdade, porém, é que adormecidas essas disposições naturais pelo desuso, em que nos cria uma educação insensata, assistimos cegos e surdos a uma infinidade de fatos, e deixamos passar desapercebidas um número inumerável de coisas, que constituiriam por si sós o fundamento de toda nossa instrução durante a existência inteira.

As preocupações de Rui Barbosa voltavam-se para um método de ensino e programas escolares capazes de suscitar o espírito científico, a curiosidade e o gosto pela experimentação, sintonizados com as diferentes etapas do desenvolvimento humano.

Segundo Lourenço Filho (1956, p. 32), Rui Barbosa, ao destacar a importância do método de ensino, assim se expressou:

Reforma dos métodos e reforma do mestre: eis, numa expressão completa, a reforma escolar inteira; eis o progresso todo, e, ao mesmo tempo, toda a dificuldade contra a mais endurecida de todas as rotinas - a rotina pedagógica. Cumpre renovar o método, orgânica, substancial, absolutamente, nas nossas escolas. $\mathrm{Ou}$, antes, cumpre criar o método, porquanto o que existe entre nós, usurpou um nome que só por antífrase lhe assentaria: não é o método de ensinar, é pelo contrário, o método de inabilitação para aprender.

Para ele, a racionalidade do método desde a escola primária deveria se assentar na investigação dos fatos. Daí a ênfase atribuída ao desenvolvimento da capacidade de observação, de comparação por analogia e contraste, classificação e indução de leis como meio de ativar a atividade intelectual das crianças.

Atento às dificuldades dos professores em adaptar as idéias de Pestalozzi, Rui Barbosa decidiu traduzir e adaptar a $18^{\text {a }}$ edição americana da obra de Calkins (1880), Primary object lessons. Adaptada à realidade brasileira, sua versão, sob o título Primeiras liçôes de coisas, foi publicada no Rio de Janeiro, em 1886, pela Imprensa Nacional.

O objetivo de Rui Barbosa não era trazer apenas a contribuição de um formulário de lições de coisas, mas documentar uma nova orientação pedagógica desenvolvida nos países mais adiantados e colocar, pela primeira vez, os mestres brasileiros em contato com as idéias pestalozzianas.

$\mathrm{Na}$ geografia, a aplicação do método intuitivo muito contribuiu para repensar aspectos pedagógico-didáticos e psicológicos da matéria a ser 
O método intuitivo e a percepção sensorial como legado de Pestalozzi...

ensinada, transformando o ensino dessa disciplina em um assunto realmente interessante para a educação elementar.

Como sócio efetivo do Instituto Histórico e Geográfico, ${ }^{9}$ Rui Barbosa, ao defender a inclusão do ensino de geografia no rol das disciplinas que compunham a estrutura curricular do ensino primário e secundário, estabeleceu as bases iniciais do ensino dessa ciência. Para ele, dentre as disciplinas escolares, a geografia, em razão de sua própria singularidade e fascínio, destacava-se como a mais indicada aos interesses e motivaçôes do dinamismo psicológico e físico das crianças. Essa afinidade talvez explique o fato de o maior avanço verificado na sua proposta metodológica ter sido nessa disciplina.

Com base nos princípios pestalozzianos, Rui Barbosa criticou severamente os manuais de geografia adotados nas escolas primárias, considerando-os crimes pedagógicos. Para evidenciar a diferença entre o modelo pedagógico predominante nas escolas brasileiras e o ensino intuitivo, Rui Barbosa (apud Proença, 19[-], p. 29), ao analisar os manuais elementares de geografia utilizados nas escolas primárias, apresentou o seguinte comentário sobre a Pequena geografia da tnfância:

Depois de algumas definições geométricas, que ocupam as duas primeiras páginas do texto, outras definiçōes constituem o intróito, definição da geographia, das linhas e dos círculos do globo, dos pólos, do horizonte, clima, latitude, longitude e estações do anno, continente, região, paiz, ilha, peninsula, cabo, isthmo, monte, montanha, serra, vulcão, mar, oceano, golfo, estreito, mancha, passo, lago e rio. Enfiado este rosário de abstracçōes inintelligíveis ao espírito despreparado da criança, segue-selhe immediatamente a tarefa de decorar o número total de kilômetros e habitantes em cada continente, a lista das religiōes e raças humanas, com a distribuição pelas várias partes e Estados, que se presuppõem assim conhecidos antes de aprendidos, as phases da civilização e as formas de governo, rematando tudo pelo questionário do costume [sic].

Também chamou a atenção para o fato de esses manuais iniciarem o estudo de geografia pela Europa, Ásia, África e América, ao invés de iniciar pelo estudo do próprio município e de seu país.

Conforme escreve Proença, ([19-], p. 30) após análise desses manuais, Rui Barbosa chegou à seguinte conclusão: "Praticado assim pelo bordão da rotina, o ensino da geographia é inútil, embrutecedor. Nullo como meio de cultura, incapaz mesmo de atuar duradoiramente na me- 
mória, não faz senão oprimir, cançar e estupidificar a infância, em vez de esclarece-la e educa-la [sic]".

O posicionamento crítico de Rui Barbosa fundamentou-se na proposta pestalozziana, segundo a qual deve-se ir do conhecido ao desconhecido, ou seja, partir dos lugares que cercam os alunos, tais como a sala de aula, a posição relativa das coisas (carteiras, jardim, pátio), até chegar à construção de uma carta geográfica. Por meio de exemplos, deve-se realizar definições de termos geográficos, sempre partindo do município para o estado, do estado para a região e, finalmente, para o país. Nas palavras de Penteado (1984, p. 109-110):

Tudo isso sempre dentro da aplicação de exercícios intuitivos, consubstanciando o ensino pelo aspecto; iniciando-se o curso pela topografia local, com amplo desenvolvimento de exercícios práticos, acompanhados das indispensáveis excursões, das representações gráficas e cartográficas adaptadas ao nível de desenvolvimento e possibilidades individuais de cada aluno.

A compreensão de Rui Barbosa acerca das possibilidades de aplicação do método intuitivo a essa disciplina antecipa traços do movimento escolanovista, uma vez que atribui especial significado à importância da atividade própria do aluno. Isso pode ser constatado na tradução que realizou do prefácio da última edição do livro do pedagogo norte-americano, Arnold Guyot (apud Penteado, 1984, p. 108): "Em obediência aos princípios que regem o método pestalozziano, os alunos, sempre que ele o permite, são introduzidos gradualmente a descobrir, eles mesmos, o que se lhes pretende ensinar, em vez de o aprenderem por informação do livro, ou do mestre".

Em relação ao ensino verbalista, o ensino intuitivo representa um avanço. No entanto, na análise de Proença ([19-], p. 50), a proposta defendida por Pestalozzi e pelos autores que preconizaram a geografia local como fundamento do estudo do mundo, não atingiu a dimensão almejada. Sobre isso explica:

Mas, ou porque se não comprehenda a finalidade deste ensino, ou porque exija elle preparação pedagógica especial, ou, ainda, porque falte ao professor liberdade para applicação de processos intuitivos, a verdade é que a geographia local não tem saído dos programmas, ou, então, tem se manifestado com physionomia tão desnaturada que ninguém acreditará tratar-se de um estudo das coisas mediante exercícios da intelligência [sic]. 
O método intuitivo e a percepção sensorial como legado de Pestalozzi...

A respeito dessa questão, o próprio Rui Barbosa, citado por Penteado (1984, p. 96), reconheceu a dificuldade de os professores, educados sob a orientação da antiga tradição escolar, colocarem em prática o método do ensino intuitivo. Mesmo porque, além da boa vontade dos professores, a prática desse ensino requer:

(...) muita experiência, flexibilidade de espírito e grande senso pedagógico. Não se trata mais de ensinar e fazer recitar uma lição, trata-se em relação a cada professor, de combinar ele mesmo o seu programa, segundo as necessidades de seus alunos, e depois de executá-lo por um contínuo dispêndio da sua própria pessoa, por uma justa solução de meios variados, apelando alternativamente para a imaginação, para o raciocínio, para o juízo, para a memória, para os sentidos, para a reflexão.

As idéias pedagógicas de Pestalozzi, introduzidas no Brasil por Rui Barbosa, demarcam a corrente pedagógica tradicional, denominada Pedagogia Intuitiva. Seu aspecto característico é oferecer, na medida do possível, dados sensíveis à percepção e observação dos alunos. Essa pedagogia fundamentava-se na psicologia sensualista, cujos representantes afirmavam que toda a vida mental se estrutura baseando-se nos dados dos sentidos, ou empregando um vocabulário pedagógico, valendo-se do concreto. Considerando-se esses fundamentos, pode-se adotar o conhecimento, até então abordado independentemente da realidade, a partir da observação do real. Conforme Aebli (1973, p. 13):

É inegável que o ensino intuitivo, (...) constitui um progresso imenso em relação ao ensino verbalista da Idade Média e da Renascença. Seu valor repousa, com efeito, no fato de preencher uma das condiçôes indispensáveis à aquisição da maioria das noções e operações: a utilização no ensino, de certos dados intuitivos (figuras geométricas, objetos, ilustrações, modelos, relevos etc.). É somente com tais materiais que as noçôes e operações podem ser elaboradas.

A principal crítica que se faz a essa pedagogia é quanto à posição passiva do aluno no processo de assimilação dos conhecimentos transmitidos por meio da utilização de todos os sentidos. As operações efetivas são executadas somente pelo professor ou, no máximo, por um aluno chamado diante da classe. Como argumenta Medeiros (1975, p. 53), nesse processo o “(...) concreto é mostrado, apresentado, demostrado, mas o aluno não mergulha nele, não age sobre ele, não o integra plenamente, por o 
não ter manipulado com as mãos e com o cérebro". Desse modo, aprender significa para a criança tirar uma cópia da explicação dada pelo professor. A criança deve, portanto, memorizar os resumos, definições, conceitos, tais como lhe foram dados e aplicar invariavelmente os mesmos procedimentos para achar soluções.

No limite de suas possibilidades teóricas, faltou a Pestalozzi o esclarecimento de como a criança poderia desenvolver o pensamento abstrato. $\mathrm{Na}$ verdade ao ficar absorvido com o poder da impressão sensorial, não foi além do conhecido mote: primeiro as coisas, depois as palavras. Não entendia, à época, que as palavras deveriam ter também um significado.

Posteriormente renomados pedagogos e psicólogos como Dewey, ${ }^{10}$ Piaget, ${ }^{11}$ Vygotsky, ${ }^{12}$ entre outros, avançaram na teorização do desenvolvimento do pensamento abstrato. Esse fato em muito contribuiu para o enriquecimento das idéias de Pestalozzi, em especial no que se refere à importância da percepção sensorial no processo de aquisição do conhecimento. Nesse sentido, pode-se dizer que muitas das idéias e princípios pestalozzianos, como o principio metódico do próximo para o distante, a prática das excursões, o estudo da geografia local e a valorização da percepção sensorial na aquisição da aprendizagem encontram-se presentes nas atuais propostas de ensino, porém enriquecidos pelas reflexões de renomados teóricos do pensamento pedagógico e geográfico contemporâneo.

\section{Recebido em maio de 2005 e aprovado em julho de 2005.}

\section{Notas}

1. Esse regulamento tinha conotaçôes políticas claras. Foi estabelecido em um contexto em que os Hohenzollen, sem dúvida a casa real mais importante do Reich pós-medieval, já haviam delineado o seu projeto político essencial: a unificação de todas as fragmentadas unidades alemãs em um poderoso Estado-nação (a Alemanha). E, futuramente, revelou-se de um significado extraordinário, na medida em que lançou os primeiros passos para a constituição, no século XIX, de uma rede de escolas públicas de âmbito nacional (Vlach, 1988).

2. Jean Jacques Rousseau (1712-1778) é natural de Genebra, na Suíça. Dentre suas principais obras pode-se destacar: Discurso sobre a origem da desigualdade entre os homens, Do contrato social, ambas sobre política, e Emílio ou $\mathrm{Da}$ educação. A respeito dessa última obra o livro de Callai, O espaço e a geografia na obra de Rousseau (1996), apresenta importantes informaçóes sobre as idéias de Rousseau presentes no ideário dos conteúdos de geografia que hoje são desenvolvidos nas escolas.

3. João Amós Comênio (1592-1670) é considerado o maior educador e pedagogo do século VII. Produziu uma obra fecunda e sistemática, cujo principal livro é Didática magna. Nesse livro Comênio apresenta uma proposta de reforma da escola e do ensino e lança as bases 
para uma pedagogia que prioriza a "arte de ensinar" por ele denominada "Didática", em oposição ao pensamento pedagógico predominante até então.

4. Segundo Cambi (1999), Basedow (1723-1790) é um dos principais teóricos do movimento pedagógico conhecido como "filantropismo" (amor à humanidade). Em 1774, fundou o instituto Filantropium, onde muitas idéias iluministas foram colocadas em prática. Basedow postulou uma educação que deveria dar condições para o homem ser feliz, e uma aprendizagem prática e agradável. Em razão disso, enfatizou a importância do estimulo da razão e da intuição no processo de educação infantil. Seu pensamento foi bastante difundido, e muito contribuiu para tornar o ensino alemão menos antiquado.

5. Como observa Ostuni (1967), para compreender os antecedentes do objetivo fundamental da investigação riteriana, ou seja, demonstrar a estreita união que há entre os fenômenos sociais humanos e as forças naturais na localidade, devemos reportar-nos a Sferten em 1807. Momento em que Ritter, ao entrar em contato com Pestalozzi, Nieder (filósofo) e Tohler (geógrafo), percebe o empenho desse grupo em fazer da geografia uma ciência vivaz, tentando estabelecer o elo que há entre o quadro natural, e o desenvolvimento histórico e civil dos povos.

6. O ensino superior de geografia brasileira inicia-se em 1934, quando da implantação da Faculdade de Filosofia, Ciência e Letras da Universidade de São Paulo. No mesmo ano foi fundada a Associação dos Geógrafos Brasileiros (AGB). No ano seguinte também foi organizado no Rio de Janeiro um curso superior de Geografia na Universidade do Distrito Federal, atual Universidade Federal do Rio de Janeiro (Andrade, 1987).

7. A produção educacional de Rui Barbosa foi elaborada no decorrer do período de 1881 a 1886. No livro A pedagogia de Rui Barbosa, Lourenço Filho (1956, p.14) o inclui no rol dos grandes pedagogistas pelo fato de que foi sem “(...) dúvida, no Brasil, o primeiro a tratar da pedagogia como problema integral de cultura, isto é, problema filosófico, social, político e técnico a um só tempo".

8. Johann Friedrich Herbart (1766-1841) foi um pedagogo alemão que exerceu relevante influência na Didática e na prática docente. Suas idéias encontram-se presentes nas salas de aula brasileiras, particularmente o que se refere à proposta de organização da prática docente: preparação e apresentação da matéria, assimilação, generalização, e aplicação.

9. O Instituto Histórico e Geográfico Brasileiro foi fundado em 1838, na cidade do Rio de Janeiro, como filial da Sociedade Auxiliadora da Indústria Nacional, por sua vez criada em 1828 , tendo por objetivo o progresso da agricultura, lavoura e indústria agrícola e pastoril do Brasil. De acordo com Vlach (1988), os membros desse Instituto tinham conhecimento das proposições de Ritter, acerca da geografia como “(...) a ciência das relaçōes terrestres espaciais” e estreitamente relacionada à história, "(...) a ciência das relaçôes terrestres temporais".

10. John Dewey nasceu em 1859 em Burlinton e faleceu 1952 em Nova York. Cursou doutorado em filosofia na Universidade de Johns Hopkins, em Baltimore. Iniciou sua carreira docente em Michigan. Freqüentou, como professor convidado, várias Universidades Inglaterra, Rússia, Japão e México. Do ponto de vista epistemológico, elaborou uma filosofia pragmatista, conhecida nos Estados Unidos como a "Escola de Chicago".

11. Sobre a produção de Jean Piaget (1896-1980) pode-se destacar como mais significativas para o ensino de geografia: $O$ desenvolvimento do pensamento: equilibrações das estruturas cognitivas; Os mecanismos da percepção; A criança e a construção da realidade; Da lógica da criança à lógica do adolescente; A representação do espaço na criança e $A$ imagem mental das crianças, estas últimas em co-autoria com Barbel Inhelder. 
12. Na produção sobre o ensino de geografia, particularmente a partir da década de 1990 , os trabalhos mais citados de Lev Semyonovich Vygotsky (1896-1934) são: A formação social da mente (1987); Pensamento e linguagem (1987) e Linguagem e desenvolvimento da aprendizagem (1988), em co-autoria com Luria \& Leontiev.

\section{Referências bibliográficas}

AEBLI, H. Didática psicológica. São Paulo: Nacional; EDUSP, 1973.

AIRES, L.L. Antologia de Pestalozzi. Buenos Aires: Losada, 1946.

BARBOSA, R. Reforma do ensino primário e várias instituições complementares da instrução pública (1883). In: BARBOSA, R. Obras completas. Rio de Janeiro: Ministério da Educação e Saúde, 1946. v.10, t.2.

CAMBI, F. História da pedagogia. Trad. Álvaro Lorencini. São Paulo: UNESP, 1999.

CAPEL, H. Filosofia y ciência en la geografia contemporânea: una introducción a la geografia. 3. ed. Barcelona: Barcanova, 1988.

EBY, F. História da educação moderna. Porto Alegre: Globo, 1962.

LIBÂNEO, J.C. Didática. São Paulo: Cortez, 1991.

LOURENÇO FILHO, M.B. A pedagogia de Rui Barbosa. 2. ed. São Paulo: Melhoramentos, 1956.

LUZURIAGA, L. Antologia de Pestallozi. Buenos Aires: Losada, 1946.

LUZURIAGA, L. História da educação e da pedagogia. São Paulo: Nacional, 1959.

MANACORDA, M.A. História da educação: da Antigüidade aos nossos dias. Trad. Galeano L. Mônaco. São Paulo: Cortez, 1989.

MEDEIROS, M.A.B. As três faces da pedagogia. 2. ed. Lisboa: Livros Horizonte, 1975.

PENTEADO, J.A. A consciência didática no pensamento pedagógico de Rui Barbosa. São Paulo: Nacional, 1984.

PENTEADO JUNIOR, O.A. Rousseau e o método de ensino. Revista de Pedagogia, São Paulo, v. 8, n. 15, jan./dez. 1962. 
O método intuitivo e a percepção sensorial como legado de Pestalozzi...

PESTALOZZI, J.H. Antologia de Pestalozzi. Trad. Lorenzo Luzuriaga. Buenos Aires: Losada, 1946.

PROENÇA, A. F. Como se ensina geographia. São Paulo: Melhoramentos, [19--]. v.7

ROUSSEAU, J.-J. Emílio. Trad. Roberto Leal Ferreira. São Paulo: Martins Fontes, 1995. 